
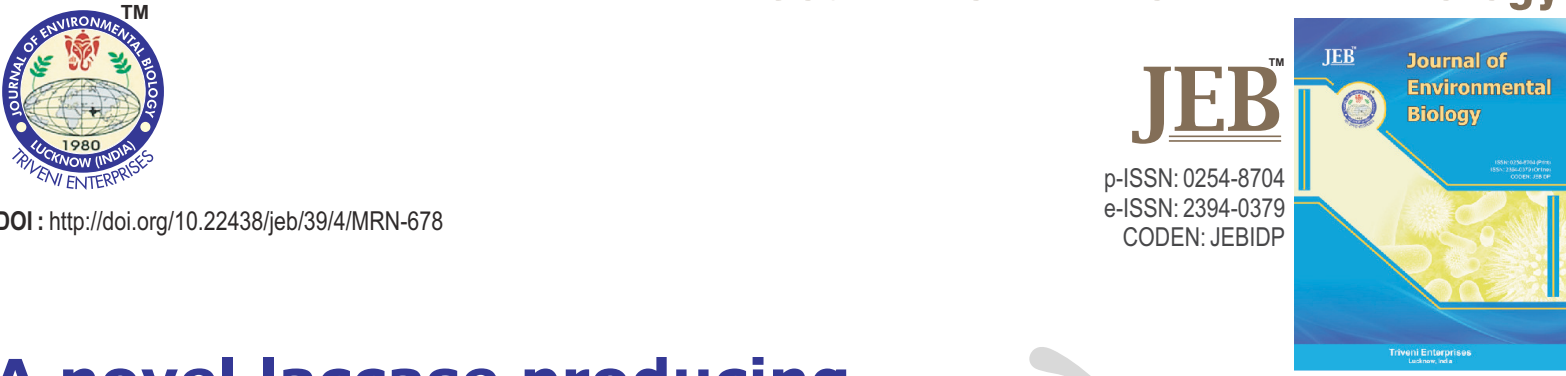

\title{
A novel laccase producing Brevundimonas sp. MVSP from paper and pulp industry waste water
}
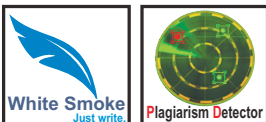

Authors Info

Palanisamy Poornima and Manickam Velan*

Department of Chemical Engineering, A.C. College of Technology, Anna University, Chennai-600 025, India

*Corresponding Author Email : velan@annauniv.edu,

Key words

Brevundimonas sp. MVSP

Laccase activity

Paper and pulp

Publication Info

Paper received : 17.06.2017

Revised received : 15.12 .2017

Accepted : 30.12 .2017

\section{Abstract}

Aim : The present study deals with the isolation, screening and characterization of laccase producing bacterial strain from paper and pulp industry waste water. A novel laccase producing bacterial strain Brevundimonas sp. MVSP was identified and the optimum conditions required for maximal laccase enzyme activity was determined.

Methodology : Serial dilution method was used for screening laccase producing strain. Out of 58 isolated microorganisms, seven positive strains were screened. Among the seven isolates, "MVSP" showed highest enzyme activity towards laccase production. The isolated microorganism was characterized by biochemical tests and molecular analysis. The 16S rRNA sequence data were analysed and the results were compared with Genbank database.

Results : Various operating parameters such as incubation time, $\mathrm{pH}$, temperature, carbon and nitrogen sources were optimized for intensification of laccase activity. On the basis of laccase activity, Brevundimonas genus was found to have higher laccase activity among the other isolates, and was determined using phylogenetic analysis. The sequence received the Gen Bank accession number KP712776. The crude enzyme isolated from Brevundimonas sp. MVSP strain showed the maximum laccase activity of $5.24 \mathrm{U} \mathrm{ml}^{-1}$ at the optimum conditions.

Interpretation : This is the first report which claims that Brevundimonas sp. MVSP produced laccase enzyme using $\mathrm{CuSO}_{4}$ and guaiacol as an inducer. The novel Brevundimonas sp. MVSP strain had achieved maximum laccase activity of $5.24 \mathrm{U} \mathrm{ml}^{-1}$ at optimized pH (6.5) and temperature $\left(35^{\circ} \mathrm{C}\right)$ in $96 \mathrm{hr}$. This potent organism could be a suitable candidate for the large-scale production of laccase and it may be used to treat various industrial effluents from textile, paper and pulp industry etc.

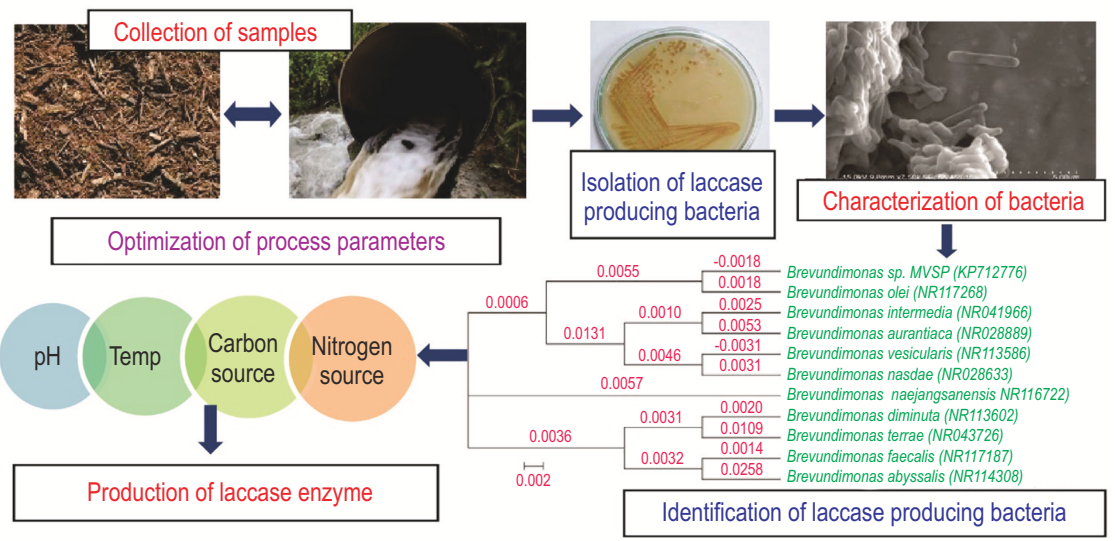




\section{Introduction}

Laccase production has been a significant attention in scientific community since it has a wide range of applications in many industries including chemical, food, paper and pulp, biofuel production, pharmaceutical and textile industries etc. (Plácido and Capareda, 2015). Laccase (benzenediol : oxygen oxidoreductase) is an excellent multi-copper containing polyphenol oxidase which acts on various substrates from one laccase to another. Laccase is widely distributed in living organisms including bacteria, insects, higher plants and fungi (Alexandre and Zhulin, 2000). Several reports are available for fungal laccase such as Ascomycetes, Basidiomycetes and Deuteromycetes (Brijwani et al., 2010). The production of laccase was also found in some prokaryotic species such as Azospirillum lipoferum (Givaudan et al., 1993), Bacillus sphaericus (Claus and Filip 1997), Escherichia coli (Uthandi et al., 2012), Marinomonas mediterranea (Solano et al., 1997), Pseudomonas putidia (Sharma et al., 2007) Pseudomonas syringae (Mellano and Cooksey, 1988) and Streptomyces griseus (Endo and Ueda, 2003), respectively. Both the bacterial and fungal laccases are similar in structures but they found to differ in their amino acid sequences. Though laccase is found in various sources, fungal laccase is widely isolated and used in many industrial applications (Baldrian, 2006). Most of the fungal and plant laccase are extracellular in nature, whereas bacterial laccase is intracellular (Diamantidis et al., 2000). The property of laccase from bacteria and fungi varies, based on their metabolic pathway. For instance, the stability of fungal laccase is low compared to bacterial laccase (Baldrian, 2006). It is interesting to note that the bacterial laccase is highly active and more stable at wider $\mathrm{pH}$, temperature levels and exhibits high salt tolerance (Sharma et al., 2007). The major functions of bacterial laccase such as morphogenesis, pigment biosynthesis and copper homeostasis are well established (Strong and Claus, 2011). Compared to fungal laccase, bacterial laccase has many significant advantages. In general, the production of bacterial strain can be achieved at low-cost media which is more suitable for commercial production of laccase. Bacterial laccase is used as the best biocatalyst in many research purposes due to the broad range of substrate utilization, grows at neutral $\mathrm{pH}$ and catalysed by various biochemical reactions (Lončar et al., 2014). The commercial production of bacterial laccase has not been established but few reports have been published on conventional and statistical methods on laccase production (Singh et al., 2009). Therefore, an attempt was made to investigate the production of laccase from a bacterial strain. In this study, the novel laccase producing bacterial strain Brevundimonas sp. MVSP was isolated, screened, characterized and various process parameters were optimized to intensify the production of laccase for scale up industrial process.

\section{Materials and Methods}

The wastewater samples were collected from pulp and paper industry located in the vicinity of Karur, Tamil Nadu, India.
Soil samples were collected from a depth of $10-15 \mathrm{~cm}$ below the earth's surface, near the mountaineous area of Namakkal, Tamil Nadu, India. The collected samples were stored in an air-tight polyethylene bag and maintained at $4^{\circ} \mathrm{C}$ until further use.

Isolation and screening of laccase-producing bacteria : For isolation and screening samples, $5 \mathrm{~g}$ of soil sample, $5 \mathrm{~g}$ of the degraded region of tree barks and $5 \mathrm{ml}$ of pulp and paper industry wastewater were collected and mixed. The mixture was taken in an $250 \mathrm{ml}$ Erlenmeyer flask which was suspended in $99 \mathrm{ml}$ of sterile saline solution $(0.9 \% \mathrm{w} / \mathrm{v} \mathrm{NaCl})$ (Bains et al., 2003). The flasks were then incubated at $37^{\circ} \mathrm{C}$ for $180 \mathrm{~min}$ in an orbital shaker maintained at $120 \mathrm{rpm}$. Then one $\mathrm{ml}$ of the sample was serially diluted and dilutions were spread on M162 minimal medium (Degryse et al., 1978) with an addition of $0.1 \%$ Guaiacol and $0.1 \mathrm{mM} \mathrm{CuSO}_{4}$, which was used as an inducer and incubated at $32^{\circ} \mathrm{C}$ for three days. The isolated bacterial colonies were selected and grown on nutrient agar medium containing $0.1 \%$ Guaiacol and $0.1 \mathrm{mM} \mathrm{CuSO}_{4}$ incubated for $48 \mathrm{hrs}$ at $32^{\circ} \mathrm{C}$. Isolated colonies were streaked several times until the isolates were found to be pure colonies. The positive laccase producing colonies was confirmed by the visual appearance of reddishbrown colour formation (Kuddus et al., 2013). The morphological, physiological and biochemical characteristics of laccase producing strains were examined. Isolated bacterial cultures were maintained on nutrient agar and stored at $4^{\circ} \mathrm{C}$ for further studies.

Biochemical and morphological characterization of isolates: The isolated strains were observed morphologically using highresolution Scanning Electron Microscope (SEM) (JEOL 100 Vegas 3 TESCAN SEM). Biochemical tests were performed using Hi-Assorted Biochemical test Kit, HI-MEDIA. The genomic DNA of the isolated culture was extracted following the method described by Cheng and Jiang, (2006). The 16S rRNA gene was amplified using the $16 \mathrm{~S}$ universal primers i.e., forward primer 5'AGAGTTTGATCCTGGCTCAG3' and reverse primer 5'ACGGCTACCTTGTTACGAC3' (Weisburg et al., 1991). Using polymerase chain reaction (PCR), the amplification was performed by initial denaturation at $94^{\circ} \mathrm{C}$ for $2 \mathrm{~min}$, followed by 40 cycles at $94^{\circ} \mathrm{C}$ for $45 \mathrm{sec}$, then at $55^{\circ} \mathrm{C}$ for $30 \mathrm{sec}$, and $72^{\circ} \mathrm{C}$ for 1 min, and a final extension at $72^{\circ} \mathrm{C}$ for $10 \mathrm{~min}$. PCR products were subjected to cycle sequencing using Big Dye Terminator V.1.1. (Applied Biosystems, Foster City, California) in an ABI PRISM Genetic Analyzer 3730 (Applied Biosystems). Extended products were precipitated and purified by ethanol. Sequences were evaluated with Seq scape analysis software V2.5. The 16S rRNA sequence results were analysed with BLAST program (National Centre for Biotechnology (http://blast.ncbi.nlm.nih.gov/Blast.cgi) and it was used for sequence similarity with the standard program module as default. The 16S rRNA sequence was deposited in GenBank database and accession number was retrieved.

Sequence analysis: The $16 \mathrm{~S}$ rRNA sequence was compared with other neighbour joining sequence and the multiple sequence alignment was performed by clustal $\mathrm{W}$ program and a 
phylogenetic tree were constructed using the software package MEGA (Molecular Evolutionary Genetics Analysis) version analysis tool V5.11 as described by Tamura et al. (2011).

Laccase activity assay and protein concentration : The selected positive bacterial strains were subjected to centrifugation $(10,000 \times \mathrm{g})$ for $20 \mathrm{~min}$ at $4^{\circ} \mathrm{C}$ and the supernatant was used for enzyme assay. The presence of laccase activity in the supernatant was determined spectrophotometrically at 530 $\mathrm{nm}$ using $10 \mathrm{mM}$ guaiacol as a substrate in a reaction mixture containing $100 \mathrm{mM}$ acetate buffer ( $\mathrm{pH} 5)\left(\varepsilon 465=48,000 \mathrm{M}^{-1} \mathrm{~cm}^{-1}\right)$. The change in the absorbance due to the oxidation of guaiacol was monitored at $37^{\circ} \mathrm{C}$ for $10 \mathrm{~min}$ of incubation. The enzyme activity was measured on Elico double beam SL 210 UV-Visible spectrophotometer (Elico Ltd, India). Laccase activity was expressed as International Units (IU), where one IU is defined as the amount of laccase required to oxidize one $\mu \mathrm{mol}$ of substrate per min. The protein concentration of laccase was determined using UV-Visible spectrophotometer at $280 \mathrm{~nm}$ by Lowry's method using Bovine serum albumin as standard (Lowry etal., 1951).

Effect of incubation time : The effect of incubation time on laccase activity was determined by recording the absorbance of enzyme catalysed reaction using copper sulphate and guaiacol as an inducer in the nutrient medium. Inoculation of one $\mathrm{ml}$ of 24 hrs old culture of isolated bacterial strain was kept at $35^{\circ} \mathrm{C}$ at 120 rpm for different incubation time ranging from 0-120 hrs. The samples were withdrawn at regular time intervals $(0,24,48,72$, 96 and $120 \mathrm{hrs}$ ) and the growth was measured by taking optical density at $600 \mathrm{~nm}$. The crude culture was centrifuged at 10,000 rpm for $20 \mathrm{~min}$ at $4^{\circ} \mathrm{C}$. The presence of laccase activity in the supernatant was measured at $530 \mathrm{~nm}$. The time at which the laccase showed maximum activity was noted as optimum incubation time of enzyme.

Effect of $\mathrm{pH}$ : The influence of $\mathrm{pH}$ on crude laccase activity was determined at optimum incubation time using guaiacol as a substrate in all activity assays. The reaction was subjected to different $\mathrm{pH}$ ranging from (5-7.5) with a $\mathrm{pH}$ interval of 0.5 . The reaction mixture was centrifuged at $10,000 \mathrm{rpm}$ for $20 \mathrm{~min}$ at $4^{\circ} \mathrm{C}$, and the supernatant was used to determine the laccase activity and the $\mathrm{pH}$ at which the maximum laccase activity was taken as optimum $\mathrm{pH}$. The enzyme activity was measured at $530 \mathrm{~nm}$.

Effect of temperature : The influence of temperature on crude laccase activity was determined at optimized incubation time and $\mathrm{pH}$, using guaiacol as a substrate. The reaction was subjected to different temperatures ranging from $20-45^{\circ} \mathrm{C}$ at an interval of $5^{\circ} \mathrm{C}$, respectively. The temperature, at which the crude enzyme showed maximum activity, was recorded as the optimum temperature of the enzyme. The reaction mixture was centrifuged at $10,000 \mathrm{rpm}$ for $20 \mathrm{~min}$ at $4^{\circ} \mathrm{C}$ and the fresh supernatant used to determine the laccase activity. The enzyme activity was measured at $530 \mathrm{~nm}$.

Effect of carbon sources : To analyse the effect of seven different carbon sources such as fructose, glucose, maltose, mannitol, starch and sucrose was amended at the concentration of $0.5 \%$ in the culture medium. A $100 \mathrm{ml}$ of nutrient medium was incorporated individually with $0.5 \%$ of the above-mentioned carbon sources and it was prepared with optimized pH in $250 \mathrm{ml}$ Erlenmeyer flasks. The flasks were sterilized, cooled and inoculated 24 hrs old Brevundimonas sp. MVSP at $35^{\circ} \mathrm{C}$ for an optimized time interval at $120 \mathrm{rpm}$. The culture medium from six different carbon sources were centrifuged at $10,000 \mathrm{rpm}$ for 20 $\min$ at $4^{\circ} \mathrm{C}$, and the supernatant was used to measure the enzyme activity at $530 \mathrm{~nm}$.

Effect of nitrogen sources : The culture medium was amended with the concentration $0.5 \%$ of different nitrogen sources such as peptone, yeast extract, tryptone, ammonium sulphate, sodium citrate and calcium nitrate were taken separately in a $250 \mathrm{ml}$ Erlenmeyer flask. It was then sterilized, cooled and inoculated with one $\mathrm{ml}$ of $24 \mathrm{hrs}$ old Brevundimonas sp. MVSP culture and was incubated at $35^{\circ} \mathrm{C}$ at $120 \mathrm{rpm}$. The culture medium was centrifuged at $10,000 \mathrm{rpm}$ for $20 \mathrm{~min}$ at $4^{\circ} \mathrm{C}$, and the supernatant from six different nitrogen sources were used to measure the enzyme activity at $530 \mathrm{~nm}$.

\section{Results and Discussion}

The preliminary screening of soil samples, tree barks and pulp and paper industry wastewater for bacterial strains showed the presence of fifty eight different bacterial strains. Out of fifty eight isolated microorganisms, seven positive strains were

Table 1 : Morphological and biochemical characteristics of Brevundimonas sp. MVSP

\begin{tabular}{ll}
\hline Characteristics & Brevundimonas sp. MVSP \\
\hline Colony colour & Brownish \\
Cell morphology & Slender \\
Gram's staining & - \\
Spore staining & - \\
Motility & Motile \\
Indole & + \\
Methyl-Red & - \\
Voges-Proskauer & - \\
Urease & - \\
$\mathrm{H}_{2}$ S production & + \\
Catalase test & - \\
Oxidase test & + \\
Nitrate reduction test & - \\
Dextrose & - \\
Fructose & - \\
Galactose & - \\
Lactose & - \\
Mannitol & - \\
Sucrose & + \\
\hline
\end{tabular}

The sign (-) indicates negative results and (+) indicates positive results 
screened on the nutrient media containing $0.1 \%$ guaiacol and 0.1 $\mathrm{mM} \mathrm{CuSO}_{4}$, a noble substrate, for the detection of laccase secretion. Among the seven isolates, it was observed that one strain which was visually identified as reddish-brown colour colonies (Fig. 1 A) named as Brevundimonas sp. MVSP, showed higher laccase activity. It was evident from the literature that most of the bacterial (Mongkolthanaruk et al., 2012) and fungal laccase strains (Prathibha et al., 2015) showed reddish brown formation, which denotes the laccase positive strains. This strain was supposed to be highly potent among the seven isolates, and hence Brevundimonas sp. MVSP was used for further studies. The morphological characteristics of isolated strain were further subjected under scanning electron microscope (Fig. 1 B). The biochemical and physiological characteristics were identified using $\mathrm{Hi}$ Assorted ${ }^{\mathrm{TM}}$ Biochemical test kit, which was compared with the Bergey's Manual of Systematic Bacteriology. The morphological, biochemical and physiological characteristics of strain, MVSP was similar to the genus Brevundimonas, and
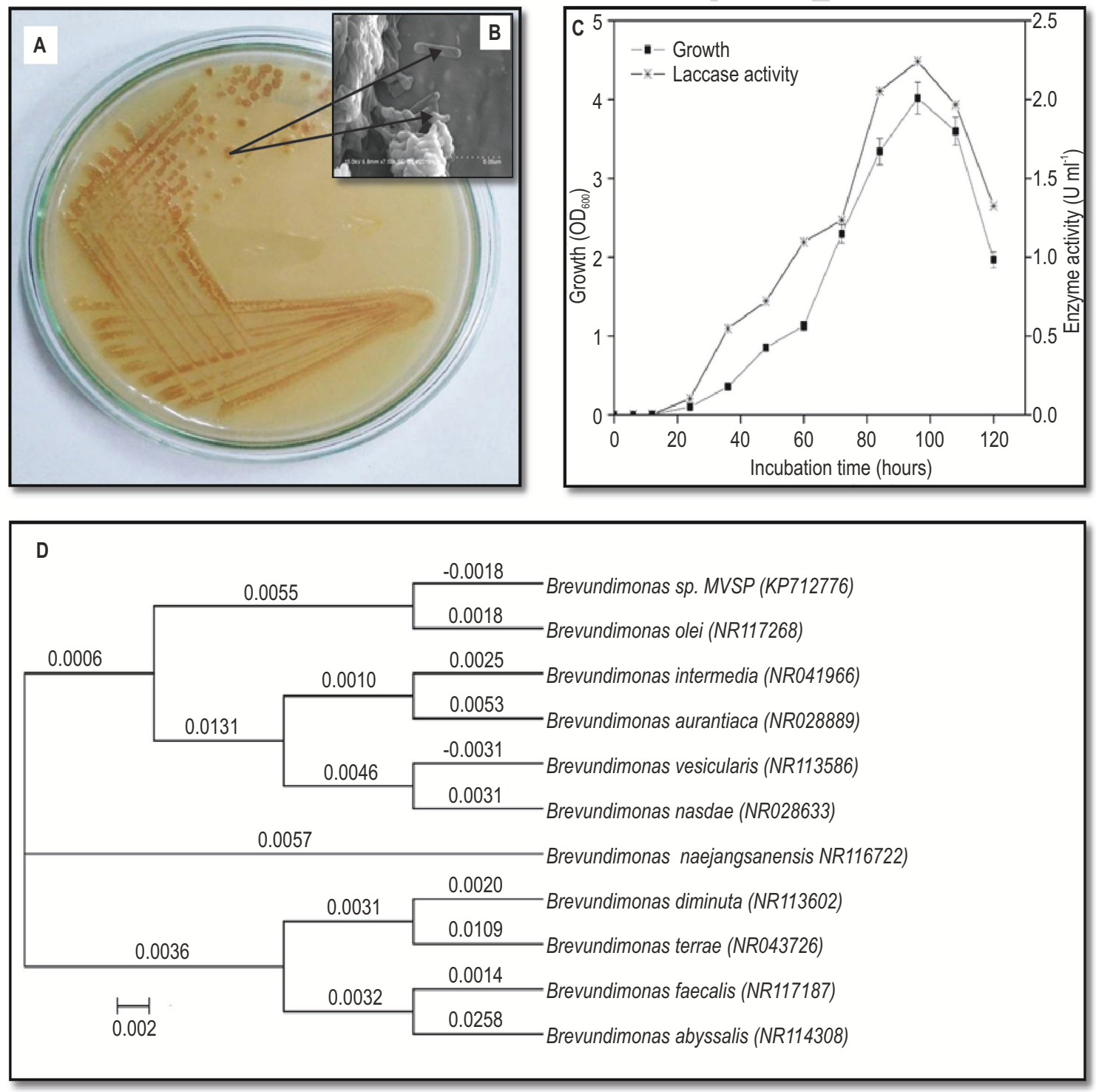

Fig. 1 (A) : Screening of novel laccase producing Brevundimonas sp. MVSP strains in nutrient agar medium, the inset (B) shows the scanning electron microscopic view of rod-shaped isolated MVSP strain, (C) Growth curve and laccase enzyme activity of Brevundimonas sp. MVSP (OD at $600 \mathrm{~nm})(\mathrm{D})$ Phylogenetic analysis of novel Brevundimonas sp. MVSP and other related Brevundimonas sp. based on 16S rRNA gene sequence. Bootstrap consensus tree was drawn by multiple sequence alignment with the neighbour-joining method using software MEGA5 


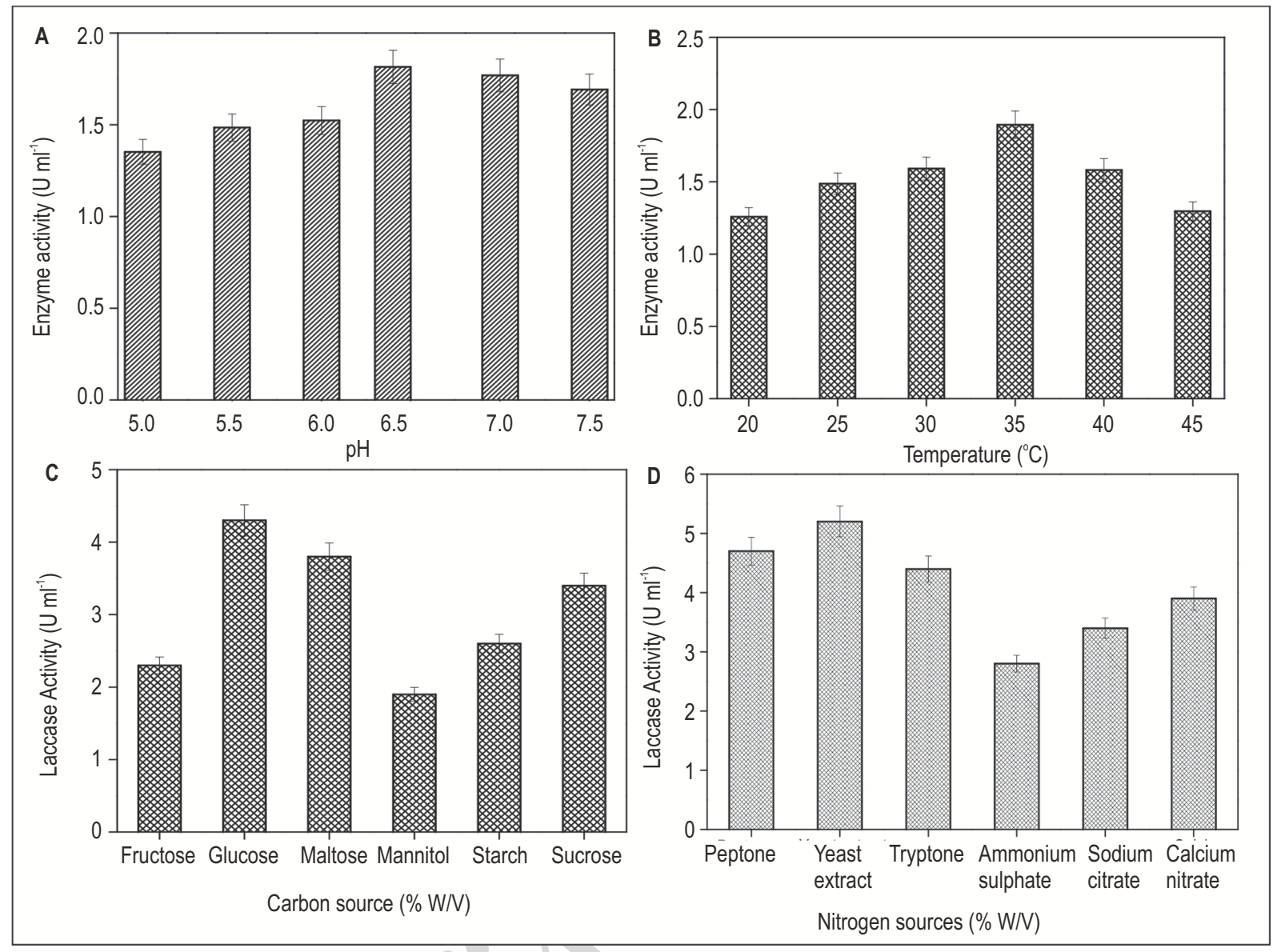

Fig. 2 (A) : Effect of pH [Conditions: Temperature: $35^{\circ} \mathrm{C}$ and Time : $120 \mathrm{hrs}$ at $120 \mathrm{rpm}$ ], (B) Temperature [Conditions: pH: 6.5, Time: $120 \mathrm{hrs}$ at $120 \mathrm{rpm}$ ], (C) Carbon sources [Conditions: $\mathrm{pH}: 6.5$, Temperature: $35^{\circ} \mathrm{C}$, Time: $120 \mathrm{hrs}$ at $120 \mathrm{rpm}$ (D) Nitrogen source on laccase enzyme activity [Conditions: $\mathrm{pH}$ : 6.5 , Temperature : $35^{\circ} \mathrm{C}$, Carbon source : glucose and Time: $120 \mathrm{hrs}$ at $\left.120 \mathrm{rpm}\right]$

hence the isolate was confirmed by performing $16 \mathrm{~S}$ rRNA sequence analysis. The biochemical and morphological test results is summarized in the Table 1 .

The PCR amplification and the 16s rRNA sequencing were performed. The retrieved $16 \mathrm{~S}$ rRNA gene sequencing was analysed using BLAST from National Centre for Biotechnology (http://blast.ncbi.nlm.nih.gov/Blast.cgi), which showed similarity to Brevundimonas sp. The phylogenetic tree analysis was closely related to Brevundimonas sp and the sequence was assigned the Gen Bank accession number KP712776. The phylogenetic tree of Brevundimonas sp. MVSP (Fig.1D) and 16S rRNA gene sequences of the strain was analysed using MEGA 5.1 software. The neighbour-joining phylogenetic tree was constructed using Kimura 2-parameter model.

Seven isolated strains were selected and screened for laccase enzyme production. Among the seven isolates,
Brevundimonas sp. MVSP was found to be a potent strain based on higher laccase activity which produced $2.24 \mathrm{U} \mathrm{ml}^{-1}$ at $96^{\text {th }}$ hrs using guaiacol, which acts as the best carbon source and inducer. The strain showed a progressive increase in enzyme activity from 24 to $96 \mathrm{hrs}$ and further increase in incubation time up to $120 \mathrm{hrs}$, the laccase activity decreased due to the decreasing phase of the bacterial strain (Fig.1C).

The newly isolated strain and its corresponding laccase activity were observed at different $\mathrm{pH}$. The maximum laccase activity of $1.815 \mathrm{U} \mathrm{ml}^{-1}$ was achieved from Brevundimonas $\mathrm{sp}$. MVSP at pH 6.5 (Fig. 2A). Similar results were observed using various substrate such as Syringaldazine (SGZ) and 2,6dimethoxyphenol (2,6-DMP) for laccases production at $\mathrm{pH} 6.5$ (Lončar et al., 2014). Lu et al. (2013a) observed that $B$. licheniformis showed the optimum $\mathrm{pH}$ of 6.2 and 6.6 for higher laccase production, when oxidized with different substrates like SGZ and 2,6-DMP respectively, and it showed similar activity as 
compared to Brevundimonas sp. MVSP. Bacillus tequilensis SN4 also showed the optimum pH as 8.0, 5.5, 6.5 and 8.0 for activity with distinct substrates such as 2,6-DMP, 2,2'-azinobis [3-ethylbenzthiazoline-6-sulfonate] (ABTS), SGZ and guaiacol, respectively. This study revealed that most of the bacterial laccase was found to be highly stable at acidic to alkaline $\mathrm{pH}$. It was observed from the study that the laccase enzyme was highly stable at the $\mathrm{pH}$ range from 6.5 to 7 . The optimum $\mathrm{pH}$ for increased activity will differ according to the substrate because every substrate causes different reactions for laccase (Shraddha et al., 2011).

The influence of temperature plays a significant role in the stability of enzyme activity. The laccase activity of isolated bacterial strain was measured at different temperatures $(25,30$, $35,40,45$ and $50^{\circ} \mathrm{C}$ ) and it can be seen from Fig. $2 \mathrm{~B}$ that an optimum laccase activity of $1.895 \mathrm{U} \mathrm{ml}^{-1}$ was achieved at $35^{\circ} \mathrm{C}$. The temperature is an important parameter which highly favours the rate of biochemical reactions, either by inducing or repressing enzyme yield (Strnadova et al., 1991). In the present study, when the experimental temperatures varied from 25$35^{\circ} \mathrm{C}$, the laccase activity increased but on further increase in temperature, the laccase activity declined due to the repression of the enzyme producing gene sequences. Similar to the study, Wang et al. (2010) also have reported that the maximum laccase activity using Bacillus subtilis WD23 was found to be at $25^{\circ} \mathrm{C}$. In another study where Streptomyces sp. C1 was used, the maximum laccase activity was achieved at $40^{\circ} \mathrm{C}$, and it was found that the enzyme was highly resistant towards high temperature (Lu et al., 2013b).

Different carbon source such as fructose, glucose, maltose, mannitol, starch and sucrose whose dosage was at a fixed concentration of $0.5 \%$ in growth medium was added to determine the intensification of laccase activity. The results showed that the isolated Brevundimonas sp. MVSP produced higher enzyme activity using glucose (4.32 $\left.\mathrm{U} \mathrm{ml}^{-1}\right)$ in the culture medium compared to other carbon sources as shown in the (Fig. 2C). Jang et al. (2002) and Ding et al. (2012) reported that glucose is an excellent carbon source for laccase production which supports the current study. In the present study, it was observed that the complete utilization of glucose was achieved at a minimum incubation time by the isolated strain compared to other carbon sources.

The nitrogen sources are essential for amino acid synthesis which makes up the proteins and other value added substances in microorganisms. In the study, six different nitrogen sources (peptone, yeast extract, tryptone, ammonium sulphate, sodium citrate and calcium nitrate) were used at fixed concentration of $0.5 \%$ to determine the effect of nitrogen sources on laccase production. The reaction was carried out at optimized incubation time ( $96 \mathrm{hrs}), \mathrm{pH}(6.5)$, temperature $\left(35^{\circ} \mathrm{C}\right)$ and carbon source (glucose). Among the six various nitrogen sources, Yeast extract added to the confined medium showed higher laccase enzyme production as seen in Fig. 2D. It was evident that the organic nitrogen sources are highly useful to enhance the laccase activity. Niladevi et al. (2007) also stated that the organic nitrogen sources showed higher laccase production than inorganic nitrogen sources using Streptomyces psammoticus. Apart from yeast extract, L-asparagine also produced increased laccase activity in Botryosphaeria rhodina (Dekker et al., 2007). Earlier reports have mentioned that the use of nitrogen sources on laccase production was doubtful (Dobson, 1997), however the present study suggest that use of yeast extract (nitrogen source) is a vital nutrient to enhance the laccase activity.

The results of this study suggests that Brevundimonas sp. MVSP strain can be further used for scale up industrial applications.

\section{Acknowledgment}

The authors would like to acknowledge the Department of Chemical Engineering, A.C. Tech, Anna University Chennai for providing necessary facilities to carry out this research work.

\section{References}

Alexandre, G. and I. B Zhulin : Laccases are widespread in bacteria. Trends Biotechnol., 18, 41-42 (2000).

Bains, J., N. Capalash and P. Sharma : Laccase from a nonmelanogenic, alkalotolerant $\gamma$-proteobacterium JB isolated from industrial wastewater drained soil. Biotechnol. Lett., 25, 1155-1159 (2003).

Baldrian, P. : Fungal laccases occurrence and properties. FEMS Microbiol. Rev., 30, 215-242 (2006).

Brijwani, K., A. Rigdon and P. V. Vadlani : Fungal laccases : Production, function and applications in food processing. Enzyme Res., doi : http : Ildx. doi. org/10.4061/2010/149748 (2010).

Cheng, H. R. and N. Jiang : Extremely rapid extraction of DNA from bacteria and yeasts. Biotechnol. Lett., 28, 55-59 (2006).

Claus, H. and Z. Filip : The evidence of a laccase-like enzyme activity in a Bacillus sphaericus strain. Microbiol. Res., 152, 209-216 (1997).

Degryse, E., N. Glansdorff and A. Pierard : Comparative analysis of extreme thermophilic bacteria belonging to genus Thermus. Arch. Microbiol., 117, 189-196 (1978).

Dekker, R. F. H., A. M. Barbosa, E. C. Giese, S. D. S. Godoy and L. G. Covizzi : Influence of nutrients on enhancing laccase production by Botryosphaeria rhodina MAMB-05. Int. Microbiol., 10, 177-185 (2007).

Diamantidis, G., A. Effosse, P. Potier and R. Bally : Purification and characterization of the first bacterial laccase in the rhizospheric bacterium Azospirillum lipoferum. Soil Biol. Biochem., 32, 919-927 (2000).

Ding, Z., L. Peng, Y. Chen, L. Zhang and G. Shi : Production and characterization of thermostable laccase from the mushroom, Ganoderma lucidum, using submerged fermentation. African J. Microbiol. Res., 6, 1147-1157 (2012).

Dobson, A. D. W. : Regulation of laccase gene transcription in regulation of laccase gene transcription in Trametes versicolor. Appl. Environ. Microbiol., 63, 3444-3450 (1997).

Endo, K. and K. Ueda : Enzymological characterization of EpoA a laccase-like phenol oxidase produced by Streptomyces griseus. J. Biochem., 5, 671-677(2003).

Givaudan, A., A. Effosse, D. Faure, P. Potier, M. L. Bouillant and R. Bally : 
Polyphenol oxidase in Azospirillum lipoferum isolated from rice rhizosphere : Evidence for laccase activity in non-motile strains of Azospirillum lipoferum. FEMS Microbiol. Lett., 108, 205-210 (1993).

Jang, M. Y., W. R. Ryu, and M. H. Cho: Laccase production from repeated batch cultures using free mycelia of Trametes sp. Enzyme Microb. Technol., 30, 741-746 (2002).

Kuddus, M., B. Joseph and P. Wasudev Ramteke: Production of laccase from newly isolated Pseudomonas putida and its application in bioremediation of synthetic dyes and industrial effluent. Biocatal Agric. Biotechnol., 2, 333-338 (2013).

Lončar, N., N. Gligorijević, N. Božić and Z. Vujčić: Congo red degrading laccases from Bacillus amyloliquefaciens strains isolated from salt spring in Serbia. Int. Biodeterior. Biodegra., 91, 18-23 (2014).

Lowry, O. H., N.J. Rosebrough, A. Lewis and R.J. Randall: Protein measurement with the Folin phenol reagent. J. Biol. Chem., 193, 265-275 (1951).

Lu, L., T. N. Wang, T. F. Xu, J. Y. Wang, C. L. Wang and M. Zhao: Cloning and expression of thermo-alkali-stable laccase of Bacillus licheniformis in Pichia pastoris and its characterization. Bioresour. Technol., 134, 81-86 (2013a).

Lu, L., G. Zeng, C. Fan, X. Ren, C. Wang, Q. Zhao, J. Zhang, M. Chen, A. Chen and M. Jiang: Characterization of a laccase-like multicopper oxidase from newly isolated Streptomyces sp. C1 in agricultural waste compost and enzymatic decolorization of azo dyes. Biochem. Eng. J., 72, 70-76 (2013b).

Mellano, M. A. and D. A. Cooksey: Nucleotide sequence and organization of copper resistance genes from Pseudomonas syringae pv. tomato. J. Bacteriol., 170, 2879-2883 (1988).

Mongkolthanaruk, W., S. Tongbopit and A. Bhoonobtong : Independent behavior of bacterial laccases to inducers and metal ions during production and activity. Afr. J. Biotechnol.,11, 9391-9398 (2012).

Niladevi, K. N., R. K. Sukumaran and P. Prema: Utilization of rice straw for laccase production by Streptomyces psammoticus in solidstate fermentation. J. Ind. Microbiol. Biotechnol., 34, 665-674 (2007).

Prathibha B. Iyer., B. Atchaya, K. Sujatha and K. Rajmohan: Comparison of synthetic dyes decolourisation by Ganoderma sp. using immobilized enzyme. J. Environ. Biol., 36, 1255-1261 (2015).

Plácido, J. and S. Capareda: Ligninolytic enzymes : A biotechnological alternative for bioethanol production. Bioresour. Bioprocess., 2, 23 (2015).

Sharma, P., R. Goel and N. Capalash: Bacterial laccases. World J. Microbiol. Biotechnol., 23, 823-832(2007).

Shraddha, R. Shekher, S. Sehgal, M. Kamthania and A. Kumar : Laccase : microbial sources, production, purification and potential biotechnological applications. Enzyme Res., 217861 (2011).

Singh, G., P. Sharma and N. Capalash: Performance of an alkalophilic and halotolerant laccase from $y$-proteobacterium JB in the presence of industrial pollutants. J. Gen. Appl. Microbiol., 55, 283-289 (2009)

Solano, F., E. García, E. Pérez De Egea and A. Sanchez-Amat: Isolation and characterization of strain MMB-1 (CECT 4803), a novel melanogenic marine bacterium. Appl. Environ. Microbiol., 63 , 3499-3506 (1997).

Strnadova, M., M. Hecker, L. Wolfel, H. Mach and J. Chaloupka: Temperature shifts and sporulation of Bacillus megaterium. J. Gen. Microbiol.,137, 787-795(1991).

Strong, P.J. and H. Claus: Laccase : A review of its past and its future in bioremediation. Crit. Rev. Environ. Sci. Technol., 41, 373-434 (2011).

Tamura, K., D. Peterson, N. Peterson, G. Stecher, M. Nei and S. Kumar : MEGA5: Molecular evolutionary genetics analysis using maximum likelihood, evolutionary distance and maximum parsimony methods. Mol. Biol. Evol., 28, 2731-2739 (2011).

Uthandi, S., L. Prunetti, IMS. De Vera, GE. Fanucci, A. Angerhofer and J. A. Maupin-Furlow: Enhanced archaeal laccase production in recombinant Escherichia coli by modification of $\mathrm{N}$-terminal propeptide and twin arginine translocation motifs. J. Ind. Microbiol. Biotechnol., 39, 1523-1532 (2012).

Wang, C. L., M. Zhao, D. Li, Bin, D. Z. Cui, H. Y. Yang, L. Lu and X. D. Wei: Isolation and characterization of a novel Bacillus subtilis WD23 exhibiting laccase activity from forest soil. Afr. J. Biotechnol., 34 5496-5502 (2010).

Weisburg, W. G., S. M. Barns, D. A. Pelletier and D. J. Lane: 16S ribosomal DNA amplification for phylogenetic study. J. Bacteriol., 173,697-703 (1991). 